\title{
Level of Plasma Tissue Factor Pathway Inhibitor is Inversely Correlated With Intraarterial Diastolic Pressure in Subjects Who Underwent Coronary Angiography
}

\author{
Hiroshi Masuoka, MD; Masaaki Ito, MD*; Shigeru Kamei, MD; \\ Morihiro Ozaki, MD; Atsushi Kawasaki, MD; Takeshi Nakano, MD*
}

\begin{abstract}
There are only a few studies of the relationship between hemostatic abnormalities and intraarterial pressure, so the present study investigated the association of various newer lipid and hemostatic variables with intraarterial pressure levels. Levels of total cholesterol, high-density lipoprotein cholesterol (HDL-C), low-density lipoprotein cholesterol, triglyceride, lipoprotein-(a), remnant-like particle cholesterol, cholesteryl ester transfer protein, uric acid, blood glucose, fibrinogen, free form of tissue factor pathway inhibitor (TFPI), C-reactive protein, serum amyloid A protein, anti-Chlamydia pneumoniae immunoglobulin $\mathrm{G}$ and immunoglobulin $\mathrm{A}$, and apolipoproteins (apo) A-I, B, and E were measured in 176 patients who underwent diagnostic coronary angiography. Intraarterial blood pressure was determined from central aortic pressure using a standard fluid-filled catheter-external transducer system. Multivariate regression analyses showed that TFPI level was the only independent factor associated with aortic diastolic pressure. The linear regression equation demonstrated a significant negative correlation of TFPI level with aortic diastolic pressure $(\mathrm{r}=-0.395, \mathrm{p}=0.0011)$. With respect to the association with other parameters, the TFPI level showed significant correlations between the HDL-C level and the apo A-I level, both in the overall patients and in the patients with coronary artery stenosis. This is the first evidence that the level of the plasma free form of TFPI is inversely correlated to aortic diastolic pressure. (Jpn Circ J 2001; 65: 165-170)
\end{abstract}

Key Words: Blood pressure; Diastolic blood pressure; TFPI; Tissue factor

A lthough effective blood pressure-lowering therapies have been introduced, hypertension is still associated with increased cardiovascular morbidity and mortality! Thus, factors other than increased blood pressure may contribute to the residual risk of cardiovascular complications in hypertensive subjects. Recently, hemostatic abnormalities have been recognized as a risk factor for cardiovascular disease, but there have been only a few studies on hemostatic abnormalities in hypertensive subjects.

Tissue factor (TF) is the primary initiator of the extrinsic coagulation cascade. It has been recognized as an initial trigger for blood coagulation in normal hemostasis ${ }^{2}$ and plays a major role in thrombogenesis associated with atherosclerosis? Tissue factor pathway inhibitor (TFPI) is the major physiological inhibitor of the TF-mediated coagulation pathway 4,5 and it is a Kunitz-type serine protease inhibitor consisting of 276 amino acids with 2 major molecular weights of 34 and $41 \mathrm{kDa} 6$ A recently developed sensitive enzyme-linked immunosorbent assay for TFPI has made it possible to measure the plasma TFPI antigen levels? so we designed the present study to evaluate the association of various newer lipid and hemostatic variables, including TFPI, with intraarterial pressure.

(Received October 2, 2000; revised manuscript received November 29, 2000; accepted December 5, 2000)

Division of Cardiology, National Mie Central Hospital, and *First Department of Internal Medicine, Mie University School of Medicine, Mie, Japan

Mailing address: Hiroshi Masuoka, MD, Division of Cardiology, National Mie Central Hospital, 2158-5 Myouzin-cho, Hisai, Mie 5141101, Japan

\section{Methods}

\section{Study Population}

The study population comprised 248 consecutive patients who underwent diagnostic coronary angiography for possible coronary artery disease. Patients who had liver disease, renal disease, endocrinologic disorders, collagen disease, neoplasm, disseminated intravascular coagulation, history of excessive alcohol drinking, or acute inflammatory disease were excluded. Patients who had had an acute myocardial infarction or other thromboembolism within the previous month were also excluded. The final study group was limited to 176 patients. None of the patient was being treated with anticoagulants or thrombolytic agents, such as urokinase, streptokinase, or alteplase, and none had prosthetic heart valves or pacemakers. Causes of secondary hypertension were excluded, as far as possible, by the appropriate clinical and laboratory findings. Written informed consent was obtained from each of the 176 patients before the study, the protocol of which was approved by the Ethics Committee of the hospital.

\section{Study Protocol}

Coronary angiography was carried out mainly through the percutaneous brachial approach, and occasionally through the femoral approach, using the standard Judkin's technique. At least 5 views of the left coronary artery and 3 of the right were obtained. According to the reporting system of the American Heart Association, narrowing of more than $51 \%$ stenosis was considered significant.

Cardiac output was also measured angiographically in each patient. Left ventricular stroke volume was estimated 
Table 1 Characteristics of the Total Patients Studied and Comparison Between 2 Subgroups Based on Diastolic Pressure

\begin{tabular}{lcccc}
\hline \hline & \multirow{2}{*}{ Total } & \multicolumn{2}{c}{ Subgroups } & \multirow{2}{*}{ p value } \\
\cline { 3 - 3 } & & Higher & Lower & \\
\hline No. of cases & 176 & 73 & 103 & 0.015 \\
Age (years) & $62.1 \pm 10.3$ & $59.6 \pm 11.1$ & $63.9 \pm 9.4$ & 0.307 \\
Male gender $(\%)$ & 71.0 & 74.0 & 68.9 & 0.001 \\
Height $(\mathrm{cm})$ & $159.8 \pm 9.5$ & $162.8 \pm 9.6$ & $157.7 \pm 9.2$ & 0.032 \\
Body weight $(\mathrm{kg})$ & $62.0 \pm 11.2$ & $64.5 \pm 11.1$ & $60.2 \pm 11.0$ & 0.962 \\
BMI $\left(\mathrm{kg} / \mathrm{m}^{2}\right)$ & $24.2 \pm 3.5$ & $24.2 \pm 3.0$ & $24.2 \pm 3.8$ & $<0.0001$ \\
BP systolic $(\mathrm{mmHg})$ & $123.5 \pm 21.9$ & $132.2 \pm 19.5$ & $117.6 \pm 21.6$ & $<0.0001$ \\
BP diastolic $(\mathrm{mmHg})$ & $66.8 \pm 11.4$ & $77.3 \pm 7.9$ & $59.6 \pm 7.1$ & 0.0001 \\
BP mean $(\mathrm{mmHg})$ & $89.6 \pm 13.9$ & $100.5 \pm 11.6$ & $82.6 \pm 10.4$ & 0.519 \\
Cardiac output $(\mathrm{L} / \mathrm{min})$ & $5.03 \pm 1.82$ & $5.17 \pm 1.57$ & $4.95 \pm 1.95$ & 0.731 \\
Heart rate $($ beats/min) & $71.3 \pm 12.6$ & $72.4 \pm 12.2$ & $71.7 \pm 12.7$ & 0.115 \\
Coronary stenosis $(\%)$ & 71.6 & 75.3 & 68.9 & \\
\hline
\end{tabular}

Data are mean $\pm S D$ or percent of patients. Higher, patients with diastolic aortic pressure $\geq 70 \mathrm{mmHg}$; Lower, patients with diastolic pressure <70 mmHg; p value, comparison between 'Higher' and 'Lower'. BMI, body mass index; BP systolic, aortic systolic pressure; BP diastolic, aortic diastolic pressure; BP mean, aortic mean pressure; Heart rate, mean heart rate through the cardiac catheterization.

by measuring the left ventricular end-diastolic and endsystolic volumes using quantitative left ventricular angiography (Quantcor QCA, Siemens AG, Germany). Cardiac output was obtained by multiplying the stroke volume by the heart rate during angiography.

Intraarterial blood pressure (BP) was determined from the central aortic pressure using a standard fluid-filled catheter external transducer system. Pressure was measured at peak systole and at end diastole. The mean pressure was determined electronically (Polygraph EP1600, NEC, Japan).

Venous blood samples were taken with minimal venostasis from an antecubital vein under fasting and resting conditions in the morning between $07.00 \mathrm{~h}$ and $08.00 \mathrm{~h}$. Each factor was determined as follows: total cholesterol (TC; automated enzymatic method), high-density lipoprotein cholesterol (HDL-C; selective inhibition assay), low-density lipoprotein cholesterol (LDL-C; direct LDL-C enzymatic method), triglyceride (TG; automated enzymatic method), lipoprotein-(a) (Lp(a); latex immunoassay with a rabbit monoclonal anti-human $\mathrm{Lp}(\mathrm{a})$ antibody), remnant-like particle cholesterol (RLP-C; immunoadsorption assay with mouse monoclonal anti-human apolipoprotein (apo) B-100 and anti-human apo A-I immunoaffinity mixed gels. A detailed procedure is given elsewhere), cholesteryl ester transfer protein (CETP; enzyme-linked immunosorbent assay using the reagent kit, Chugai, Tokyo), uric acid (automated enzymatic method), blood glucose (automated enzymatic method), creatinine (alkaline picrate method), fibrinogen (thrombin time), C-reactive protein (CRP; lethitin immunoassay), serum amyloid A protein (SAA; latex agglutination nephelometric immunoassay. A detailed procedure is given elsewhere) $)^{10}$ anti-Chlamydia pneumoniae immunoglobulin $\mathrm{G}(\mathrm{Cp}-\mathrm{IgG})$ and immunoglobulin $\mathrm{A}(\mathrm{Cp}-$ $\mathrm{IgA}$; microimmunofluorescence), and apo A-I, B, and $\mathrm{E}$ (turbidimetric immunoassays using the reagent kit, Apo Auto Daiichi, according to the manufacture's instructions)!1 The level of the free form of TFPI antigen was also measured with an enzyme-linked immunosorbent assay kit using anti-human TFPI IgG purified from rabbit serum (Kaketsuken, Kumamoto) according to the manufacturer's instructions? This assay has been shown to be specific, sensitive, reproducible, and appropriate for routine clinical application. Normal values for TFPI by this assay have been reported as $9-23 \mathrm{ng} / \mathrm{ml}$. A detailed procedure of this assay is given elsewhere ${ }^{12}$ All lipid-lowering drugs were withdrawn at least 14 days before the study. Body mass index (BMI) was calculated as weight divided by height squared $\left(\mathrm{kg} / \mathrm{m}^{2}\right)$.

\section{Statistical Analysis}

Student's unpaired 2-tailed t test was used for comparisons between 2 groups. Mann-Whitney's U test was performed if data sets were not normally distributed. Discrete data were analyzed by the chi-square test. Multivariate regression analysis was also performed to determine the association of intraaortic pressure and various parameters. Correlations among parameters were tested with Pearson's correlation coefficient. A logarithmic transformation was performed when the variances in parameters were skew. Statistical analyses were performed by Stat View version 4.5 (Abacus concepts Inc Berkeley, CA, USA) using an Apple computer. $\mathrm{p}<0.05$ was considered significant in each test.

\section{Results}

\section{Patient Characteristics}

The mean age of the 176 patients studied was $62.1 \pm 10.3$ years $($ mean \pm SD) and ranged from 31 to 79 years. There were 125 males and 51 females. Coronary angiography revealed that 50 patients had no significant coronary artery stenosis or occlusion and 126 had significant organic stenosis. The number of patients who were found to have 1-, 2-, or 3-vessel and left main disease in the latter group was 59, 40,20 , and 7, respectively. Baseline characteristics of the overall patients studied are shown in Table 1. Their plasma creatinine concentrations were all normal.

The clinical diagnoses confirmed following coronary angiography were as follows: myocardial infarction in 47 cases, angina pectoris in 82 cases, silent myocardial ischemia in 4 cases, positive stress test in 14 cases, neurocirculatory asthenia in 19 cases, cardiomyopathy in 4 cases, valvular heart disease in 3 cases, and arteriosclerosis obliterans in 3 cases.

\section{Correlation of Various Parameters With Aortic Pressure}

To assess the correlation between aortic pressure and the levels of the various variables, multivariate regression analyses were performed (Table 2). Because a highly significant correlation was observed between TC and LDL-C ( $\mathrm{r}=0.882)$, we excluded TC from the covariate. Cp-IgA was also excluded because it correlated to $\mathrm{Cp}-\mathrm{IgG}$. Values of $\mathrm{TG}$, 
Table 2 Multivariate Statistical Analyses for Correlations of Aortic Pressure With Various Lipid and Hemostatic Parameters

\begin{tabular}{|c|c|c|c|c|}
\hline \multirow{2}{*}{ Parameter } & \multicolumn{2}{|c|}{ Systolic pressure $\left(r^{2}=0.424\right)$} & \multicolumn{2}{|c|}{ Diastolic pressure $\left(r^{2}=0.439\right)$} \\
\hline & Coefficient & $p$ value & Coefficient & $p$ value \\
\hline$L D L-C$ & -0.203 & 0.580 & 0.482 & 0.187 \\
\hline$H D L-C$ & 0.666 & 0.213 & -0.649 & 0.215 \\
\hline$T G$ & 0.478 & 0.306 & 0.111 & 0.806 \\
\hline $\operatorname{Lp}(a)$ & -0.231 & 0.303 & 0.196 & 0.371 \\
\hline$R L P-C$ & -0.426 & 0.252 & -0.023 & 0.948 \\
\hline Аро A-I & -0.152 & 0.719 & 0.569 & 0.175 \\
\hline Apo B & 0.069 & 0.894 & -0.745 & 0.145 \\
\hline Apo $E$ & 0.153 & 0.512 & 0.055 & 0.808 \\
\hline CETP & 0.033 & 0.867 & -0.074 & 0.677 \\
\hline Uric acid & 0.242 & 0.193 & 0.107 & 0.552 \\
\hline Glucose & 0.235 & 0.247 & 0.211 & 0.287 \\
\hline Fibrinogen & 0.348 & 0.064 & 0.084 & 0.679 \\
\hline TFPI & -0.263 & 0.176 & -0.467 & 0.011 \\
\hline$C R P$ & -0.312 & 0.103 & -0.189 & 0.307 \\
\hline$S A A$ & -0.142 & 0.499 & 0.097 & 0.638 \\
\hline$C p-\operatorname{Ig} G$ & -0.193 & 0.323 & -0.021 & 0.911 \\
\hline Creatinine & 0.077 & 0.699 & 0.234 & 0.232 \\
\hline
\end{tabular}

LDL-C, low-density lipoprotein cholesterol; HDL-C, high-density lipoprotein cholesterol; TG, triglyceride; Lp(a), lipoprotein-(a); RLP-C, remnant-like particle cholesterol; Apo A-I, apolipoprotein A-I; Apo B, apolipoprotein B; Apo E, apolipoprotein E; CETP, cholesteryl ester transfer protein; TFPI, tissue factor pathway inhibitor; CRP, C-reactive protein; SAA, serum amyloid A protein; Cp-IgG, anti-Chlamydia pneumoniae immunoglobulin $G$.

Table 3 Comparison of the Lipid and Hemostatic Parameters Between Patients With an Aortic Diastolic Pressure of $70 \mathrm{mmHg}$ or Higher (Higher) and Those With Values Lower Than $70 \mathrm{mmHg}$ (Lower)

\begin{tabular}{|c|c|c|c|}
\hline & Higher & Lower & $p$ value \\
\hline$T C(m g / d l)$ & $195.1 \pm 32.1$ & $193.9 \pm 39.7$ & 0.833 \\
\hline$L D L-C(m g / d l)$ & $120.8 \pm 27.9$ & $119.0 \pm 35.8$ & 0.740 \\
\hline$H D L-C(m g / d l)$ & $45.4 \pm 10.9$ & $49.8 \pm 12.6$ & 0.099 \\
\hline$T G(m g / d l)$ & $146.9 \pm 59.2$ & $129.3 \pm 62.0$ & 0.056 \\
\hline$L p(a)(m g / d l)$ & $31.5 \pm 42.5$ & $34.0 \pm 35.0$ & 0.691 \\
\hline$R L P-C(\mathrm{mg} / \mathrm{dl})$ & $5.43 \pm 2.50$ & $5.30 \pm 2.74$ & 0.623 \\
\hline Apo A-I $(\mathrm{mg} / \mathrm{dl})$ & $122.4 \pm 19.9$ & $123.4 \pm 21.3$ & 0.783 \\
\hline Apo B $(\mathrm{mg} / \mathrm{dl})$ & $107.4 \pm 21.3$ & $105.2 \pm 26.6$ & 0.587 \\
\hline Apo $E(m g / d l)$ & $4.29 \pm 1.09$ & $4.10 \pm 1.03$ & 0.282 \\
\hline$C E T P(\mu \mathrm{g} / \mathrm{ml})$ & $2.62 \pm 0.61$ & $2.88 \pm 0.82$ & 0.139 \\
\hline Uric acid $(\mathrm{mg} / \mathrm{dl})$ & $6.05 \pm 1.72$ & $5.89 \pm 1.72$ & 0.566 \\
\hline Glucose $(\mathrm{mg} / \mathrm{dl})$ & $110.8 \pm 31.3$ & $104.8 \pm 22.9$ & 0.193 \\
\hline Fibrinogen $(\mathrm{mg} / \mathrm{dl})$ & $333.9 \pm 78.4$ & $323.8 \pm 77.6$ & 0.185 \\
\hline TFPI $(\mathrm{ng} / \mathrm{ml})$ & $20.94 \pm 4.88$ & $24.01 \pm 7.38$ & 0.007 \\
\hline$C R P(m g / d l)$ & $0.348 \pm 0.667$ & $0.307 \pm 0.472$ & 0.265 \\
\hline$S A A(\mu \mathrm{g} / \mathrm{ml})$ & $29.8 \pm 87.6$ & $17.4 \pm 66.7$ & 0.417 \\
\hline$C p-\operatorname{Ig} G$ & $1.40 \pm 1.04$ & $1.39 \pm 0.85$ & 0.929 \\
\hline$C p-\operatorname{Ig} A$ & $1.39 \pm 0.87$ & $1.43 \pm 0.75$ & 0.847 \\
\hline Creatinine $(\mathrm{mg} / \mathrm{dl})$ & $0.83 \pm 0.19$ & $0.82 \pm 0.24$ & 0.878 \\
\hline
\end{tabular}

TC, total cholesterol; Cp-IgA, anti-Chlamydia pneumoniae immunoglobulin A; Other abbreviations as in Table 2.

Lp(a), RLP-C, TFPI, glucose, fibrinogen, CRP, SAA, and $\mathrm{Cp}-\mathrm{IgG}$ were transformed into natural logarithms. Multivariate analysis showed that TFPI level was the only independent factor associated with aortic diastolic pressure. No significant correlation was observed between any variable and aortic systolic pressure.

We divided the patients into 2 subgroups according to the aortic diastolic pressure (Table 1): $\geq 70 \mathrm{mmHg}$ or higher as the higher pressure subgroup $(\mathrm{n}=73) ;<70 \mathrm{mmHg}$ as the lower pressure subgroup $(\mathrm{n}=103)$. The mean height and body weight were higher in the higher pressure subgroup, but no significant difference was observed in the mean BMI value. There was also no significant difference in cardiac output between the 2 subgroups.

The comparison of the mean levels of lipid and hemostatic components in these 2 subgroups is shown in Table 3 . The levels of TFPI showed a significant difference between the 2 subgroups and TFPI was again the only variable that showed significant difference in this analysis. The levels of TG tended to be high in the higher diastolic pressure subgroup with marginal significance $(\mathrm{p}=0.056)$.

The linear regression equations relating the TFPI levels to aortic pressures are shown in Figs 1 and 2. TFPI was negatively correlated with aortic diastolic pressure, as shown in Fig 1 ( $\mathrm{r}=-0.395, \mathrm{p}=0.0011)$. In contrast, no statistically significant correlation was observed between TFPI and aortic systolic pressure, as demonstrated in Fig 2 ( $r=$ $0.044, \mathrm{p}=0.583$ ).

\section{Correlation of TFPI Level With Various Parameters}

The TFPI level may be influenced by age, sex, obesity, or hyperlipidemia. Little information is available concerning 
TFPI level (ng/ml)

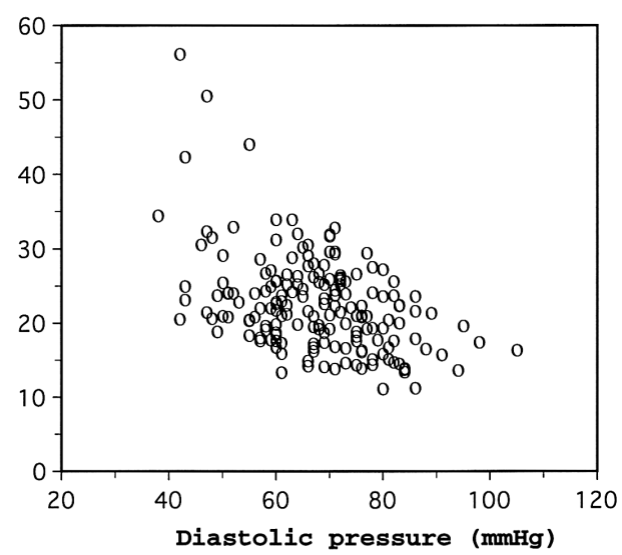

Fig 1. Correlation between aortic diastolic pressure and the level of tissue factor pathway inhibitor (TFPI). The linear regression equation for diastolic pressure: TFPI $=32.26-0.142 \times$ pressure, $\mathrm{R}^{2}=0.080$, $\mathrm{p}=0.0018$.
TFPI level (ng/ml)

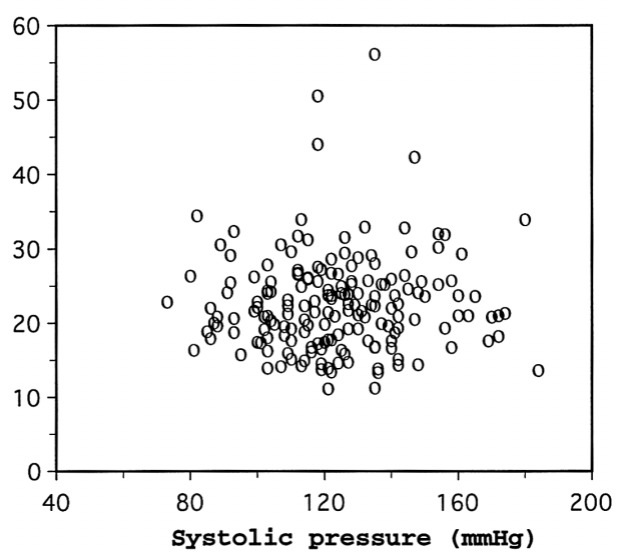

Fig 2. Correlation between aortic systolic pressure and the level of tissue factor pathway inhibitor (TFPI). The linear regression equation for diastolic pressure: TFPI $=22.12-0.013 \times$ pressure, $\mathrm{R}^{2}=0.002$, $\mathrm{p}=0.583$.

Table 4 Simple Correlation Coefficients for Tissue Factor Pathway Inhibitor Levels in the Total Patients Studied and in Patients With Coronary Artery Stenosis

\begin{tabular}{lcccc}
\hline \hline & \multicolumn{2}{c}{ Total patients } & & \multicolumn{2}{c}{ Patients with coronary stenosis } \\
\cline { 2 - 3 } Age & $r$ & $p$ & $r$ & $p$ \\
Height & 0.152 & 0.097 & 0.150 & 0.120 \\
Body weight & -0.130 & 0.117 & -0.178 & 0.109 \\
BMI & -0.126 & 0.118 & -0.201 & 0.087 \\
Cardiac output & -0.072 & 0.387 & -0.131 & 0.341 \\
TC & 0.116 & 0.308 & 0.041 & 0.510 \\
LDL-C & 0.163 & 0.082 & 0.131 & 0.104 \\
HDL-C & 0.077 & 0.339 & 0.041 & 0.572 \\
TG & 0.270 & 0.022 & 0.346 & 0.013 \\
Lp(a) & -0.026 & 0.752 & -0.051 & 0.599 \\
RLP-C & 0.025 & 0.755 & 0.009 & 0.927 \\
Apo A-I & 0.090 & 0.264 & 0.054 & 0.475 \\
Apo $B$ & 0.257 & 0.004 & 0.240 & 0.012 \\
Apo $E$ & 0.084 & 0.404 & 0.046 & 0.459 \\
CETP & 0.038 & 0.640 & 0.071 & 0.696 \\
Uric acid & -0.028 & 0.819 & -0.124 & 0.528 \\
Glucose & 0.056 & 0.486 & 0.053 & 0.582 \\
Fibrinogen & 0.068 & 0.398 & 0.071 & 0.464 \\
CRP & 0.114 & 0.156 & 0.145 & 0.133 \\
SAA & 0.100 & 0.279 & 0.045 & 0.482 \\
Cp-IgG & 0.051 & 0.530 & 0.041 & 0.673 \\
Cp-IgA & -0.013 & 0.872 & -0.075 & 0.610 \\
Creatinine & -0.034 & 0.778 & -0.033 & 0.835 \\
\hline B & 0.072 & 0.372 & 0.127 & 0.277 \\
\hline body & & & & $r$ \\
\hline
\end{tabular}

BMI, body mass index; $r$, correlation coefficient. Other abbreviations as in Table 2. $p$ was determined using the Pearson correlation coefficient.

the relationships between the TFPI level and patient characteristics or various lipid and hemostatic parameters in an adequate study population, especially patients whose coronary anatomic characteristics were also evaluated. We tested the correlation between TFPI levels and all measured chemical and various physiological variables according to Pearson's rank correlation coefficient method (Table4). To evaluate an effect of the existence of coronary artery disease, we also separately analyzed the data for patients with established coronary artery stenosis. Analyses were performed in the overall patient group $(n=176)$ and in the patients who had coronary artery stenosis $(n=125)$. The correlation in the patients with coronary artery stenosis was approximately the same as that in all the patients combined.
The TFPI level showed significant correlation between the HDL-C level and the apo A-I level, both in the overall patients and in the patients with coronary artery stenosis. The TFPI levels tended to increase as the age of the subjects increased, but the difference did not reach a statistical significance.

We also compared the TFPI levels among some clinical subgroups. The mean $\pm \mathrm{SD}$ of the TFPI level in male subjects was $22.43 \pm 6.21 \mathrm{ng} / \mathrm{ml}$ and that in female subjects was $23.53 \pm 7.53 \mathrm{ng} / \mathrm{ml}$, showing no significant difference $(\mathrm{p}=0.407)$. The mean TFPI level in the older subjects (age $\geq 62$ years, $n=89$ ) was $23.61 \pm 6.84 \mathrm{ng} / \mathrm{ml}$ and that in the younger subjects $(\mathrm{n}=87)$ was $22.37 \pm 7.13 \mathrm{ng} / \mathrm{ml}$, showing no significant difference $(\mathrm{p}=0.271)$. The mean TFPI level 
in the hypercholesterolemic subjects ( $\mathrm{TC} \geq 220 \mathrm{mg} / \mathrm{dl}, \mathrm{n}=37$ ) was $22.65 \pm 8.41 \mathrm{ng} / \mathrm{ml}$ and that in the normocholesterolemic subjects $(n=139)$ was $22.78 \pm 6.11 \mathrm{ng} / \mathrm{ml}(\mathrm{p}=0.633)$. The mean TFPI level in the hypertriglyceridemic subjects (TG $\geq 150 \mathrm{mg} / \mathrm{dl}, \mathrm{n}=62$ ) was $23.06 \pm 5.74 \mathrm{ng} / \mathrm{ml}$, whereas that in the normotriglyceridemic subjects $(n=114)$ was $22.65 \pm 7.07$ $\mathrm{ng} / \mathrm{ml}(\mathrm{p}=0.296)$. The mean TFPI level in the hyper-remnant lipoproteinemic subjects ( $\mathrm{RLP}-\mathrm{C} \geq 6.0 \mathrm{mg} / \mathrm{dl}, \mathrm{n}=58$ ) was $23.15 \pm 6.05 \mathrm{ng} / \mathrm{ml}$, and that in the lower-remnant lipoproteinemic subjects (RLP-C $<6.0 \mathrm{mg} / \mathrm{dl}, \mathrm{n}=118$ ) was $22.65 \pm$ $6.88 \mathrm{ng} / \mathrm{ml}(\mathrm{p}=0.329)$. The mean TFPI level in patients with coronary artery stenosis was $23.34 \pm 8.83 \mathrm{ng} / \mathrm{ml}$ and that in patients without stenosis was $22.18 \pm 7.20 \mathrm{ng} / \mathrm{ml}(\mathrm{p}=0.566)$.

\section{Discussion}

TF is the primary initiator of the extrinsic coagulation cascade and is considered a major regulator of coagulation, hemostasis, and thrombosis,$^{13,14}$ as well as contributing to the procoagulant activity of most atherosclerotic lesions in the coronary artery 15 TFPI is a protease inhibitor that acts as a natural anticoagulant to regulate the TF-mediated coagulation pathway by forming complexes with Factor Xa, Factor VIIa, and TF 16,17 TF pathway inhibition by local administration of the recombinant TFPI has been reported to be effective in reducing arterial thrombosis in human atherosclerotic lesions, ${ }^{12}$ so TFPI could serve as an essential natural anticoagulant protecting against potential thrombotic complications? Our current investigation demonstrates for the first time that a significant correlation exists between circulating levels of the free form of TFPI and intraarterial pressure in humans. Decreased levels of TFPI might be one possible reason for the high incidence of cardiovascular complications in hypertensive subjects and may accelerate atherosclerosis by exposing vascular luminal wall surfaces to persistent and recurrent thrombi.

In the present study, the plasma levels of the free form of TFPI correlated with aortic diastolic pressure, but not with aortic systolic pressure, which is interesting because ascending aortic pressure has a greater effect on coronary perfusion during diastole than systole. Both increased resistance and increased stiffness elevate systolic pressure ${ }^{18}$ In contrast, diastolic pressure rises with increased resistance, but falls with increased stiffness; the relative contribution of each determines the ultimate diastolic pressure 19 Diastolic pressure is determined by cardiac output and peripheral vascular resistance ${ }^{20}$ so an increase in diastolic pressure could result from either a high cardiac output or impaired vasodilatation of the resistance vessels. Cardiac output correlated with neither intraarterial pressure nor TFPI level in our present study (Tables 1,4), so we speculate that the association of TFPI level with intraarterial pressure is a consequence of the change in vascular resistance. Brett et al reported that the change from resting values in diastolic but not in systolic BP during exercise correlated with the serum cholesterol level. ${ }^{21}$ They speculated that the impaired vascular reactivity related to the serum cholesterol level influences the change in systemic vascular resistance and hence diastolic BP. However, the mechanism by which only diastolic pressure was related to TFPI level in our study remains uncertain.

The inaccuracy of the cuff technique in predicting the diastolic BP has been reported. Cuff-measured diastolic pressures systematically overestimate the intraarterial brachial artery pressures 22 With the most careful cuff measurement, true systolic BP is underestimated by $0-5 \mathrm{mmHg}$ and true diastolic BP overestimated by $10-15 \mathrm{mmHg}$ or more compared with simultaneous intraarterial pressure recording.1,23 Values of the ascending aortic pressure in subjects with no cardiovascular disease have not been fully described because of the necessarily invasive nature of direct aortic pressure measurement. The mean value of the aortic diastolic pressure in the current study group, shown in Table 1, is similar to the value obtained from the overall catheter studies in the past 3 years at the same hospital $(66.0 \pm 10.4 \mathrm{mmHg}$, range 38-107).

The association of TFPI level with aortic diastolic pressure in our current study was independent of lipid parameters. Some prior reports indicated that associations exist between the TFPI level and lipid parameters, although data are conflicting. There is emerging evidence that the TFPI levels correlate with TC levels ${ }^{17,24,25}$ and LDL-C levels, 26,27 but one study reported no relation between them 28 Some studies have revealed an association between the TFPI levels and the HDL-C levels, 27,29 but others have not found such a relationship? 26 Some studies found a negative correlation between TFPI levels and TG levels, ${ }^{27}$ but again others have not 26,29

In the present study, the level of the free form of TFPI showed significant positive correlations with the HDL-C and apo A-I levels. Although it also tended to correlate positively with the TC level, the difference did not reach statistical significance $(p=0.082$, Table 4$)$. One possible explanation for these discrepancies among the other reports and ours might be the difference in methodology. Our present concern was the estimation of the level of the free form of TFPI, whereas the total TFPI levels were considered in most of the other reported correlations. The importance of the free form in relation to the anticoagulant activity of vascular endothelial cells has been reported ${ }^{24}$ Lindahl et al ${ }^{30}$ suggested that the free form of TFPI has greater anticoagulant activity relative to amidolytic activity than lipoproteinassociated TFPI. Therefore, it is noteworthy that the free form of TFPI correlated positively with HDL-C and apo A-I in the present study. We cannot exclude the possibility that the lack of correlation between the TFPI level and TC or other lipid parameters in this study are related to an inadequate power because of the small sample size.

Significantly higher levels of BP and TG, and lower HDL$\mathrm{C}$ levels compared with control subjects have been noted in patients with syndrome $\mathrm{X} 3{ }^{3}$ In the present study, only the TG level tended to be high in the higher diastolic pressure subgroup with marginal significance, probably because the number of patients was small. In contrast, the profound difference between the higher pressure subgroup and the lower pressure subgroup in the TFPI level suggests that the finding is less likely because of chance alone.

There was a significant difference in the mean age between the higher and lower aortic diastolic pressure groups (Table 1). The TFPI levels tended to increase as the age of the subjects increased, although the difference did not reach a statistical significance. Such being the case, we compared the TFPI levels between an older patient subgroup and a younger patient subgroup and found no significant difference between them. This finding lessens the likelihood that the correlation of TFPI with intraarterial diastolic pressure is the result of age difference. However, we admit that additional studies dealing with large numbers of patients will be required to rule out the possibility that the correlation of TFPI with intraarterial diastolic pressure is influenced by age difference. 


\section{Conclusion}

The study provides the first evidence that the level of plasma free TFPI is inversely correlated to aortic diastolic pressure, which might partially explain the high incidence of cardiovascular complications in hypertensive subjects.

\section{Acknowledgments}

This work was supported in part by the Research Grant for Cardiovascular Diseases (11C-6) from the Ministry of Health and Welfare in Japan. We thank Mrs Setsuko Masuoka for her help in preparing the manuscript.

\section{References}

1. Meade TW: The epidemiology of atheroma, thrombosis and ischaemic heart disease. In: Bloom AL, Forbes CD, Thomas DP, Tuddenham EGD, editors. Haemostasis and thrombosis. London: Churchill Livingstone, 1994: 1199-1227

2. Nemerson Y: Tissue factor and haemostasis. Blood 1988; 71: 1-8

3. Wilcox JN, Smith KM, Scwartz SM, Gordon D: Localization of tissue factor in the normal vessel wall and in the atherosclerotic plaque. Proc Natl Acad Sci USA 1989; 86: 2839-2843

4. Broze GJ, Girard TJ, Novotny WF: Regulation of coagulation by a multivalent Kunitz-type inhibitor. Biochemistry 1990; 29: 7539-7546

5. Rappaport SI: The extrinsic pathway inhibitor: A regulator of TFdependent blood coagulation. Thromb Haemost 1991; 66: 6-10

6. Lindahl AK, Sandset PM, Abildgaard U: The present status of tissue factor pathway inhibitor. Blood Coagul Fibrinolysis 1992; 3: 439-449

7. Abumiya T, Enjyoji K, Kokawa T, Kamikubo Y, Kato H: An anti tissue factor pathway inhibitor (TFPI) monoclonal antibody recognized the third Kunitz domain (K3) of free form of TFPI but not lipoprotein-associated forms in plasma. J Biochem 1995; 118: $178-$ 182

8. Nakajima K, Saito T, Tamura A, Suzuki M, Nakano T, Adachi M, et al: Cholesterol in remnant-like lipoproteins in human serum using monoclonal anti B-100 and anti apo A-I immunoaffinity mixed gels. Clin Chim Acta 1993; 223: 53-71

9. Austen WG, Edwards JE, Frye RL, Gensini GG, Gott VL, Griffith LSC, et al: A reporting system on patients evaluated for coronary artery disease: Report of the Ad Hoc Committee for Grading of Coronary Artery Disease, Council on Cardiovascular Surgery, American Heart Association. Circulation 1975; 51: 5-40

10. Nakayama T, Sonoda S, Urano T, Yamada T, Okada M: Monitoring both serum amyloid protein A and C-reactive protein as inflammatory markers in infectious diseases. Clin Chem 1993; 39: 293-297

11. Ikeda T, Shibuya Y, Senba U, Sugiuchi H, Araki S, Uji Y, et al: Automated immunoturbidimetric analysis of six plasma apolipoproteins: Correlation with radial immunodiffusion assays. J Clin Lab Anal 1991; 5: 90-95

12. Haskel EJ, Torr SR, Day KC, Palmier MO, Wun T-C, Sobel BE, et al: Prevention of arterial reocclusion after thrombolysis with recombinant lipoprotein-associated coagulation inhibitor. Circulation 1991; 84: $821-827$

13. Rappaport SI, Rao VM: Initiation and regulation of tissue factordependent blood coagulation. Arterioscler Thromb 1992; 12: 1111-
1121

14. Fuster V, Fallon JT, Nemerson Y: Coronary thrombosis. Lancet 1996; 348: $\mathrm{S} 7-\mathrm{S} 10$

15. Marmur JD, Thiruvikraman SV, Fyfe BS, Guha A, Sharma SK, Ambrose JA, et al: Identification of active tissue factor in human coronary atheroma. Circulation 1996; 94: 1226-1232

16. Girard TJ, Warren LA, Novotny WF, Likert KM, Brown SG, Miletich JP, et al: Functional significance of the Kunitz-type inhibitory domains of lipoprotein-associated coagulation inhibitor. Nature 1989; 338: $518-520$

17. Kokawa T, Enjyoji K, Kumeda K, Kamikubo Y, Harada-Shiba M, Koh H, et al: Measurement of the free form of TFPI antigen in hyperlipidemia: Relationship between free and endothelial cell-associated forms of TFPI. Arterioscler Thromb Vasc Biol 1996; 16: 802-808

18. Bellamy RF: Diastolic coronary artery pressure: Flow relations in the dog. Circ Res 1982; 50: 334-341

19. Franklin SS, Khan SA, Wong ND, Larson MG, Levy D: Is pulse pressure useful in predicting risk for coronary heart disease? The Framingham Heart Study. Circulation 1999; 100: 354-360

20. Rowell LB: Human cardiovascular control. New York: Oxford University Press, 1993: 268-291

21. Brett SE, Ritter JM, Chowienczyk PJ: Diastolic blood pressure changes during exercise positively correlate with serum cholesterol and insulin resistance. Circulation 2000; 101: 611-615

22. Smulyan H, Safar ME: The diastolic blood pressure in systolic hypertension. Ann Intern Med 2000; 132: 233-237

23. Zweifler AJ, Shahab ST: Pseudohypertension: A new assessment. $J$ Hypertens 1993; 11: 1-6

24. Kokawa T, Abumiya T, Kimura T, Harada-Shiba M, Koh H, Tsushima $\mathrm{M}$, et al: Tissue factor pathway inhibitor activity in human plasma: Measurement of lipoprotein-associated and free forms in hyperlipidemia. Arterioscler Thromb Vasc Biol 1995; 15: 504-510

25. Sandset PM, Lund H, Norseth J, Abildgaard U, Ose L: Treatment with hydroxymethylglutaryl: Coenzyme A reductase inhibitors in hypercholesterolemia induces changes in the components of the extrinsic coagulation system. Arterioscler Thromb 1991; 11: 138-145

26. Hansen JB, Huseby NE, Sandset PM, Svensson B, Lyngmo V, Nordoy A: Tissue factor pathway inhibitor and lipoproteins: Evidence for association with and regulation by LDL in human plasma. Arterioscler Thromb 1994; 14: 223-229

27. Zitoun D, Bara L, Basdevant A, Samama MM: Levels of factor VIIc associated with decreased tissue factor pathway inhibitor and increased plasminogen activator inhibitor-1 in dyslipidemias. Arterioscler Thromb Vasc Biol 1996; 1: 77-81

28. Rugeri L, Susen S, Bard JM, Corseaux D, Gaveriaux V, Devos P, et al: Monocyte tissue factor response is decreased in patients with hyperlipidemia. Thromb Res 1999; 96: 283-292

29. Sandset PM, Larsen ML, Abildgaard U, Lindhal AK, Odegaard OR: Chromogenic substrate assay of extrinsic pathway inhibitor (EPI): Levels in normal population and relation to cholesterol. Blood Coagul Fibrinolysis 1991; 2: 425-433

30. Lindahl AK, Jacobsen PB, Sandset PM, Abildgaard U: Tissue factor pathway inhibitor with high anticoagulant activity is increased in postheparin plasma and in plasma from cancer patients. Blood Coagul Fibrinolysis 1991; 2: 713-721

31. Swan JW, Walton C, Godsland IF, Crook D, Oliver MF, Stevenson JC: Insulin resistance syndrome as a feature of cardiological syndrome $\mathrm{X}$ in non-obese men. Br Heart J 1994; 71: 41-44 